\title{
Antipsychotic agents: efficacy and safety in schizophrenia
}

This article was published in the following Dove Press journal:

Drug, Healthcare and Patient Safety

28 November 2012

Number of times this article has been viewed

\author{
Arão Nogueira de Araújo' \\ Eduardo Pondé de Sena ${ }^{1,2}$ \\ Irismar Reis de Oliveira ${ }^{1,3}$ \\ Mario F Juruena ${ }^{4}$ \\ 'Postgraduation Program in \\ Interactive Processes of Organs \\ and Systems, ${ }^{2}$ Department \\ of Pharmacology, Institute of \\ Health Sciences, ${ }^{3}$ Department of \\ Neurosciences and Mental Health, \\ School of Medicine, Federal University \\ of Bahia, Salvador, Brazil; ${ }^{4}$ Stress \\ and Affective Disorders Program, \\ Department of Neuroscience and \\ Behavior, Faculty of Medicine of \\ Ribeirao Preto, University of Sao \\ Paulo, Sao Paulo, Brazil
}

\begin{abstract}
Antipsychotics have provided a great improvement in the management of people with schizophrenia. The first generation antipsychotics could establish the possibility of managing many psychotic subjects in an outpatient setting. With the advent of the second (SGA) and third generation antipsychotics (TGA), other psychiatric disorders such as bipolar depression, bipolar mania, autism, and major depressive disorder have now been approved for the use of these drugs for their treatment. Also, the administration of more specific assessment tools has allowed for better delineation of the repercussions of these drugs on symptoms and the quality of life of patients who use antipsychotic agents. In general, the SGA share similar mechanisms of action to achieve these results: dopamine- 2 receptor antagonism plus serotonin-2A receptor antagonism. The TGA (eg, aripiprazole) have partial agonist activity at the dopamine-2 receptor site, and are also called dopaminergic stabilizers. The pharmacological profile of SGA and TGA may provide better efficacy against negative symptoms, and are less likely to produce extrapyramidal symptoms; however, the SGA and TGA are associated with many other adverse events. The clinician has to balance the risks and benefits of these medications when choosing an antipsychotic for an individual patient.
\end{abstract}

Keywords: antipsychotic agents, schizophrenia, pharmacology, safety

\section{Introduction}

Schizophrenia is a chronic disorder with serious physical, social, and economic consequences, with an impact on public health that has been unappreciated. Thus, it is a devastating illness that reflects in the productivity of individuals affected by it and requires permanent spending with hospitalizations, treatments, and rehabilitations. ${ }^{1,2}$ This chronic disorder is characterized by an onset in early adulthood, a lifelong course, debilitating symptoms, deterioration of functional ability, and lack of social acceptability, making it among the most disabling and economically catastrophic disorders. ${ }^{3}$

In clinical research, five symptom clusters have been described in persons with schizophrenia. They include negative, positive, excitement, cognitive, and depression and anxiety dimensions of schizophrenic psychopathology. ${ }^{4}$

Positive symptoms are associated with hospital admission. They are identified as superimposed behaviors and principally involve delusions, hallucinations, and disorganized thinking. Generally, patients experience a combination of these positive symptoms. Delusions are the most common psychotic symptoms and occur in $65 \%$ of patients with schizophrenia..$^{5-7}$ Hallucinations and disorganized thinking are present in $50 \%$ of these patients. Auditory hallucinations are the most common sensory disturbance, but visual, tactile, olfactory, and gustatory hallucinations may also be present. ${ }^{8}$
Correspondence: Eduardo Pondé de Sena Department of Pharmacology, Institute of Health Sciences, Federal University of Bahia, Avenida Reitor Miguel Calmon, $\mathrm{s} / \mathrm{n}$, Vale do Canela, Salvador, Bahia, CEP 40I I0-100, Brazil

Tel +557132417154

Fax +557132417154

Email eduponde@ufba.br 
Negative symptoms represent an absence of a normal function. They reflect a blunting or loss of a range of affective and cognitive functions. These symptoms comprise blunted affect, abulia, alogia, anhedonia, apathy, avolition, and asociality. ${ }^{7-9}$

Excitement symptoms are often related to a manic-like syndrome in patients with schizophrenia. They involve abnormalities in both the extent and nature of psychomotor activity. Particularly, they may be present in an acute phase of the disease and tend to respond well to pharmacological interventions. These symptoms are characterized by excitement, impulsivity, psychomotor activation, and uncooperativeness. ${ }^{7,10}$

Cognitive domains are also affected by the disorder, and include deficits in attention, language, memory, executive function, processing speed, and social cognition. Cognitive impairments are strong predictors of poor social and vocational outcomes. They are present in the premorbid phase of schizophrenic illness and persist throughout the long-term. ${ }^{7,11}$

Depression and anxiety symptoms are present in a majority of schizophrenia patients at some point during the course of the illness. Depression may be part of the prodrome or the florid phase; it may follow an acute psychotic episode, or occur between psychotic exacerbations. Anxiety could be considered as a cormobity. ${ }^{7}$

Treatment of schizophrenia requires long-term administration of antipsychotic drugs. Lack of efficacy, poor patient compliance, extrapyramidal symptoms (EPS), weight gain, and sedation can interfere with long-term adherence to maintenance drug therapy. ${ }^{12}$ Although atypical antipsychotic drugs have been associated with a lower risk of EPS, which include abnormal involuntary movements like parkinsonism, dystonia, akathisia, and tardive diskinesia, these drugs pose a higher risk for the development of metabolic adverse events. ${ }^{13-16}$

Since the advent of chlorpromazine, there has been a great improvement in the treatment of people with schizophrenia. From that time, other antipsychotic agents were launched until the development of the second generation antipsychotics (SGA). These new drugs (also known as atypical antipsychotics) are thought to be more efficacious in treating negative symptoms and also produce fewer side effects (eg, less EPS) when compared to the first generation antipsychotics (FGA). ${ }^{17}$

Although patients report preference for the SGA, we cannot forget the important side effects associated with their use (for instance, increased cardiometabolic risk). These drugs have different pharmacological profiles and side effects that may differ from one agent to another. ${ }^{18}$

In addition to promoting antipsychotic action without producing significant EPS, other characteristics of the SGA that define their atypicity include an absence of hyperprolactinemia and greater efficacy in positive (at least in the case of clozapine), negative, and cognitive symptoms. From a pharmacological perspective, the SGA can be defined as antagonists of the serotonin-dopamine, D2-blockers with rapid dissociation and D2 or 5HT2 partial agonists. ${ }^{19}$

For some authors, ${ }^{20-22}$ another class of antipsychotic agents for the pharmacological treatment of schizophrenia and other psychiatric disorders can be identified: the third generation antipsychotics (TGA). Aripiprazole, an example of a TGA, has functional antagonist activity under hyperdopaminergic conditions, and functional agonist properties under hypodopaminergic conditions. Aripiprazole seems to produce D2-mediated functional effects that involve a broad range of classic pharmacological intrinsic activities. These variations in both intrinsic activity and potency have suggested that aripiprazole may be "functionally selective" at D2 receptors, and not just as a simple partial agonist. $^{22}$

\section{Clinical studies}

The effectiveness of current drugs for the treatment of schizophrenia may occur in only about $50 \%$ of patients. ${ }^{23-25}$ Poor symptom response is associated with premature treatment discontinuation, symptom exacerbation, relapse, and increased risk of hospitalization with resultant higher costs of treatment. ${ }^{26-29}$ Predictors of antipsychotic response should evaluate the disease state at baseline (before the initiation of treatment) and at early symptom changes after beginning treatment. Cognitive function deficits, ${ }^{30}$ poor premorbid functioning, ${ }^{31}$ earlier age of onset,,$^{32}$ duration of untreated psychosis, ${ }^{33,34}$ and male gender ${ }^{35}$ are baseline factors that have been found to be associated with poor treatment response. Patients may remain as nonresponders if early nonresponse is observed at the first 2 weeks of treatment. Correll et $\mathrm{al}^{36}$ reported that early nonresponse to treatment, as measured by a $20 \%$ reduction in the Brief Psychiatric Rating Scale (BPRS) total score at week 1 predicted nonresponse at 4 weeks for $100 \%$ of patients. Other studies have suggested the hypothesis that early nonresponse to treatment within the first 2 weeks of treatment initiation is a good indicator of treatment refractoriness. ${ }^{37,38}$

Double-blind, controlled studies have compared SGA with FGA, most often favoring SGA insofar as greater 
symptom reduction (particularly for negative, cognitive, and affective symptoms) and better tolerability (notably regarding motor adverse effects) have been noted. In response to these positive studies, most international evidence-based guidelines advocate first-line use of SGA. ${ }^{39}$

In the Clinical Antipsychotic Trials of Intervention (CATIE) study, ${ }^{24}$ the relative effectiveness of SGA was compared with that of perphenazine in a double-blind fashion. A total of 1493 patients with schizophrenia were recruited at 57 US sites and were randomly assigned to receive olanzapine ( $7.5 \mathrm{mg}$ to $30 \mathrm{mg}$ per day), perphenazine ( $8 \mathrm{mg}$ to $32 \mathrm{mg}$ per day), quetiapine (200 $\mathrm{mg}$ to $800 \mathrm{mg}$ per day), or risperidone (1.5 $\mathrm{mg}$ to $6.0 \mathrm{mg}$ per day) for up to 18 months. Ziprasidone (40 mg to $160 \mathrm{mg}$ per day) was included after its approval by the Food and Drug Administration. The primary objective of the CATIE study was to discriminate between the differences in effectiveness of these five treatments. Before 18 months, $74 \%$ of patients discontinued the study medication (1061 of the 1432 patients who received at least one dose): $64 \%$ in the olanzapine group, $75 \%$ of those assigned to the perphenazine group, $82 \%$ of those randomized to the quetiapine group, $74 \%$ of those in the risperidone arm, and $79 \%$ of those who were assigned to the ziprasidone group. Time to the discontinuation of treatment for any cause was significantly longer in the olanzapine group than in the quetiapine $(P<0.001)$ or risperidone $(P=0.002)$ group, but not in the perphenazine $(P=0.021)$ or ziprasidone $(P=0.028)$ group. Time to discontinuation because of intolerable side effects was similar among the groups, but the rates differed $(P=0.04)$; olanzapine was associated with more discontinuation for weight gain or metabolic effects, and perphenazine was associated with more discontinuation for extrapyramidal effects. In conclusion, the majority of patients in each group discontinued their assigned treatment due to inefficacy, intolerable side effects, or for other reasons. Olanzapine was the most effective drug in terms of the rates of discontinuation, and the efficacy of the conventional antipsychotic agent, perphenazine, appeared to be similar to that of quetiapine, risperidone, and ziprasidone. However, olanzapine was associated with greater weight gain and increases in measures of glucose and lipid metabolism.

In the United Kingdom, the Cost Utility of the Latest Antipsychotic Drugs in Schizophrenia Study (CUtLASS) ${ }^{40}$ concluded that FGA (largely sulpiride) and SGA (olanzapine, risperidone, amisulpride, and quetiapine) did not differ in terms of overall efficacy as measured by the Positive and Negative Syndrome Scale (PANSS), extrapyramidal side effects, quality of life, and patient preference over a period of 52 weeks. ${ }^{40}$
Leucht et $\mathrm{al}^{15}$ published a meta-analysis comparing nine SGA and FGA for overall efficacy; positive, negative, and depressive symptoms; relapse; quality of life; EPS; sedation; and weight gain. Results showed that five SGA (aripiprazole, quetiapine, sertindole, ziprasidone, and zotepine) were not significantly different from FGA in their effects on overall, positive, and negative symptoms, whereas clozapine, amisulpride, olanzapine, and risperidone were more efficacious than FGA. Olanzapine, risperidone, and sertindole proved to be significantly better than FGA in terms of relapse prevention. With regard to quality of life, only clozapine, sertindole, and amisulpride were better than FGA.

One issue regarding the efficacy of antipsychotic agents has been pointed out by recent publications. Data from randomized clinical trials (RCT) of antipsychotics used in treating schizophrenia taken between 1991 and 2006, show that there is an increase in placebo response in more recent trials. ${ }^{41}$ Some of the contributing factors include specific participant characteristics (eg, gender, treatment resistance and previous exposure, adherence to drug treatment, diagnostic precision, and illness severity), site characteristics (eg, academic or commercial, experience and training of site staff, recruitment pressures and procedures, "recycling" of subjects), trial design issues (eg, entry requirements, timing of assessments, double-blind placebo lead-ins, concomitant medications), and other issues. ${ }^{41}$ Excessive placebo response in clinical trials includes expectancy bias (in patients and investigators), incentives, rater reliability, and data quality. ${ }^{42}$ Similar issues were observed in antidepressant RCT. The placebo response rate doubled between 1980 and $2000 .{ }^{43}$ The relatively modest effects of antidepressants (in comparison with placebo) in contemporary RCT, as well as the lack of attention being paid to the contribution of placebo expectancy factors to individual outcomes, have often been underestimated. However, the modest benefits of antidepressants observed in grouped datasets may obscure large, specific, and very meaningful therapeutic effects for $10 \%$ to $20 \%$ of those treated with antidepressants. ${ }^{44}$

On the other hand, the placebo-controlled trial is the standard method used to verify the efficacy and safety of antipsychotic agents for the treatment of schizophrenia. ${ }^{45}$ Currently, superiority over placebo is the only acceptable and reliable proof of efficacy of new antipsychotic medications. ${ }^{46,47}$ Without the placebo-controlled design, one cannot show that improvements in symptoms do not represent nonspecific treatment effects or the natural course of the disease. ${ }^{45}$ Also, in trials intended to show that a new drug is equivalent to established drugs, a variety of problems may reduce the power 
to detect clinically significant differences between the new drug and the active comparator. ${ }^{48,49}$ Furthermore, without a placebo comparator, one cannot affirm whether the apparent equivalence of the standard and the new antipsychotic drug has occurred because the clinical population recruited for a study is nonresponsive to both drugs. In addition, if the experimental drug is ineffective and/or unsafe, the larger sample size required for noninferiority testing may expose more patients to harmful side effects or ineffective treatment compared with placebo-controlled designs. ${ }^{45}$ The placebocontrolled trial can protect research participants from the harmful effects of ineffective drugs. ${ }^{50}$

In terms of the clinical efficacy of antipsychotic agents, we are usually interested in treatment response and remission. In clinical trials, the efficacy of antipsychotics is measured through the use of scales like BPRS ${ }^{51}$ or PANSS. ${ }^{52}$ Among the available trials, there is no agreement in terms of when to consider a clinical response with an antipsychotic agent; different trials report that a response could be considered when reductions from the initial scores of $20 \%, 30 \%, 40 \%$, $50 \%$, and $60 \%$ are found. ${ }^{53}$ Some studies using data from a large number of subjects, ${ }^{54-58}$ rated simultaneously with the BPRS/PANSS and the Clinical Global Impression Scale (CGI), ${ }^{59}$ concluded that a $25 \%$ reduction in the BPRS/PANSS baseline scores is associated with a minimal improvement in the CGI score; moreover, a 50\% reduction in the BPRS/ PANSS scores would correspond with "much improved" scores in the CGI.

Remission is defined as a lack of significant symptoms. To obtain a uniformly accepted definition of remission, a group of experts ${ }^{60}$ proposed that a patient can be considered as being in remission if eight items on the $\mathrm{PANSS}^{52}$ or corresponding items on the BPRS, ${ }^{51}$ Scale for the Assessment of Positive Symptoms, ${ }^{61}$ or on the Scale for the Assessment of Negative Symptoms ${ }^{56}$ are rated as being "mildly present" or better. ${ }^{62}$

Other important outcome measures in schizophrenia trials include relapse and recovery. Relapse can be defined in different ways: exacerbation or recurrence of symptoms, change in functional status or change in treatment requirements, intensity of services, or locus of care. ${ }^{53}$ Some studies define relapse when patients need to be hospitalized. ${ }^{63-69} \mathrm{We}$ have to remember that hospitalization due to social causes should not be considered as relapse. Also, some patients can be treated when presenting with worsening symptoms while avoiding hospitalization. Recovery is the goal of the treatment of patients with schizophrenia, and improvement of symptoms requires improvement of functional measures.
Recovery is influenced by psychosocial treatments, family and community supports, supportive employment, and supportive education. ${ }^{53}$

There are many scales that measure clinical efficacy in schizophrenia trials. The following scales evaluate clinical symptomatology: ${ }^{53}$

- CGI Severity and Improvement Scale ${ }^{59}$

- BPRS $^{51}$

- PANSS $^{52}$

- Scale for the Assessment of Negative Symptoms ${ }^{62}$

- Calgary Depression Rating Scale S0 $^{70}$

\section{Patient preference}

The importance of subjective measures has been repeatedly addressed in studies on the quality of life of patients with schizophrenia. ${ }^{71,72}$ Improvement in quality of life and social functioning, with consequent reintegration into society, is clearly a major goal of treatment for schizophrenia. ${ }^{17,73}$

Some studies have shown that the type of antipsychotic medication could influence treatment nonadherence. The use of atypical antipsychotics can improve adherence when compared with FGA. In some studies, the use of atypical antipsychotics was seen to be associated with greater treatment adherence relative to conventional neuroleptics. ${ }^{74-76}$

It has been suggested that better control of negative symptoms and fewer EPS during treatment with SGA are associated with better adherence to treatment. ${ }^{77}$ Moreover, some studies suggest that patients receiving SGA have better subjective responses to their current medication than those receiving conventional medications. ${ }^{78-80}$ However, a prospective study reported that there was no difference between SGA and FGA in terms of adherence to treatment. $^{81}$

Patients' subjective well-being is one important variable in the evaluation of the effects of antipsychotics and can be critical in determining compliance in schizophrenia. ${ }^{82}$ Some studies have indicated that the severity of depressive symptoms can be associated with subjective well-being. ${ }^{83-85}$ The evidence of the association between improvements in positive and negative symptoms is less consistent, suggesting that the identification and treatment of depressive symptoms in schizophrenic patients may affect perceptions of their own well-being. ${ }^{86,87}$ We can use self-report scales to measure patient outcomes, such as: ${ }^{53}$

- Drug Attitudes Inventory ${ }^{88}$

- Subjective Wellbeing under Neuroleptic Treatment Scale (original/short form) $^{89}$

- $\quad$ 36-Item Short Form Health Survey ${ }^{90}$ 
- EuroQol $^{91}$

- Sheehan Disability Scale ${ }^{92}$

Other efficacy outcome scales will focus on cognitive impairment in schizophrenia:

- Measurement and Treatment to Improve Cognition in Schizophrenia ${ }^{93}$

- CGI of Cognition in Schizophrenia ${ }^{94}$

- CogState Schizophrenia Battery ${ }^{95}$

- CogState 12-Minute Battery ${ }^{96}$

- Schizophrenia Cognition Rating Scale ${ }^{97}$

- Repeatable Battery for Assessment of Neuropsychological Status $^{98}$

- Brief Assessment of Cognition in Schizophrenia ${ }^{99}$

- Brief Cognitive Assessment Tool for Schizophrenia ${ }^{100}$

- 5-minute Digit Symbol Coding Task ${ }^{101}$

\section{Safety and tolerability}

The effectiveness of a drug is characterized by its efficacy, tolerability, safety, function, and acceptability. Many patients drop out of treatment due to the side effects of the medications. The most common side effects are EPS and sedation. ${ }^{102}$

\section{Extrapyramidal side effects}

SGA produce fewer EPS than FGA; however, when doses of SGA are increased, there is a possibility of emergence of EPS. Clozapine and quetiapine have lower affinities for the dopamine receptors, resulting in a rare association with EPS. In therapeutic dosages, clozapine only has a dopamine D2 receptor blockage of $40 \% .{ }^{102}$ In doses of 450 and $750 \mathrm{mg} /$ day, quetiapine has D2 receptor occupancies of $30 \%$ and $41 \% .{ }^{103}$ Also, these antipsychotic drugs have an antagonistic effect on the 5HT2 A receptor and a partial agonistic effect on the 5HT1 A receptor, which seems to aid in the production of low levels of EPS, and gives these medications the character of atypicality. ${ }^{102}$

On the other hand, amisulpride has a high affinity for D2/ D3 receptors, no significant binding to 5HT2 receptors, and also shows lower risk of EPS. This is because amisulpride is a unique SGA that selectively blocks D2-like receptors presynaptically in the frontal cortex, possibly enhancing dopaminergic transmission, as well as postsynaptically in the limbic areas, possibly reducing dopaminergic transmission in this region. ${ }^{104}$ In this case, an occupancy of 5HT2A receptors is not the cause of atypicality of the amisulpride, but it is likely that a fast dissociation from D2 receptors makes this drug more accommodating to physiological dopamine transmission, which permits an antipsychotic effect without EPS. ${ }^{105}$
The monitoring of EPS is important because these neurologic symptoms have been associated with poor compliance, reduced quality of life, increased suicide rates, and increased risks of developing tardive dyskinesia. ${ }^{102}$

\section{Cardiovascular and metabolic side effects}

Since the beginning of the antipsychotic era, these drugs have been known to be associated with sudden death. Prolongation of the QT interval to more than $500 \mathrm{~ms}$ has been associated with an increased risk of developing the potential fatal cardiac arrhythmia, Torsade de Pointes. However, this mechanism may be responsible (to a minor degree) for the increased mortality rate seen in patients with schizophrenia. The antipsychotic-induced metabolic changes such as weight gain, increased risk of developing diabetes, and dyslipidemia are far more important. Clozapine, olanzapine, and quetiapine are the SGA that cause the worst metabolic changes. Disturbances in glucose metabolism and diabetes mellitus can occur with the use of SGA, and are associated with increases in insulin resistance and visceral adiposity with reduced responsiveness of pancreatic beta cells to glucose. ${ }^{106}$ For olanzapine and clozapine, a direct diabetogenic effect regardless of weight gain has been established. Diabetic ketoacidosis can occur as an acute complication of antipsychotic treatment. Olanzapine and clozapine seem to have the highest prevalence of ketoacidosis, but most cases are reversible when discontinuing the offending drug.

Glycosylated hemoglobin (HbAlc) is often elevated in these patients, and decreased levels of high-density lipoprotein and increased levels of triglycerides are associated with an increased risk of insulin resistance. Dyslipidemia increases the risk of cardiovascular disease due to arteriosclerosis, and it should be noted that SGA affect both triglycerides and cholesterol levels. Results from the CATIE study suggest that clozapine, olanzapine, and quetiapine affect triglycerides and cholesterol levels the most. ${ }^{24}$ Patients with antipsychotic-induced dyslipidemia might benefit from lifestyle interventions, or they may switch to a more metabolically tolerable antipsychotic drug.

The metabolic side effects of SGA were investigated in a meta-analysis of studies comparing the metabolic side effects of the following SGA in a head-to-head comparison: amisulpride, aripiprazole, clozapine, olanzapine, quetiapine, risperidone, sertindole, ziprasidone, and zotepine. ${ }^{107}$ The authors found 48 studies with 105 treatment arms. Olanzapine was more likely to produce weight gain than risperidone, risperidone more than amisulpride, and sertindole more than risperidone. Olanzapine was more likely to produce an increase in cholesterol levels than aripiprazole, 
risperidone, and ziprasidone; no differences with amisulpride, clozapine, and quetiapine were found. Quetiapine produced a greater increase in cholesterol levels than risperidone and ziprasidone. Olanzapine produced a greater increase in glucose than amisulpride, aripiprazole, quetiapine, risperidone, and ziprasidone; no difference was found with clozapine. The authors concluded that some atypical antipsychotics produced more metabolic side effects than others. The clinician should take these side effects into consideration when choosing an atypical drug for each individual patient.

Correll et al ${ }^{108}$ investigated patients with bipolar disorder and schizophrenia who were treated with SGA. The authors concluded that these patients have similarly high rates of metabolic syndrome. The authors suggested a shared susceptibility to antipsychotic-related metabolic deregulation not primarily related to psychiatric diagnosis or concomitant mood stabilizer treatment.

\section{Conclusion}

Progress in the treatment of psychosis has occurred in the last few decades, and more recently with the introduction of new antipsychotic agents. Some new challenges are now important points that should be taken into account by the clinician, such as the safety and tolerability of antipsychotics. Ultimately, choosing the best treatment for an individual patient can result in greater adherence to medication and more success in clinical outcomes.

\section{Disclosure}

The authors report no conflicts of interest in this work.

\section{References}

1. Buckley PF. Treatment of schizophrenia: let's talk dollars and sense. Am J Manag Care. 1998;4(3):369-383.

2. Rice DP. The economic impact of schizophrenia. J Clin Psychiatry. 1999;60 Suppl 1:4-6; discussion 28-30.

3. American Psychiatric Association. Diagnostic and Statistical Manual of Mental Disorders. 4th ed. Washington DC: American Psychiatric Association; 1994.

4. Lindenmayer JP, Bernstein-Hyman R, Grochowski S. Five-factor model of schizophrenia. Initial validation. J Nerv Ment Dis. 1994; 182(11):631-638.

5. Breier A, Berg PH. The psychosis of schizophrenia: prevalence, response to atypical antipsychotics, and prediction of outcome. Biol Psychiatry. 1999;46(3):361-364.

6. Appelbaum PS, Robbins PC, Roth LH. Dimensional approach to delusions: comparison across types and diagnoses. Am J Psychiatry. 1999;156(12):1938-1943.

7. Tandon R, Nasrallah HA, Keshavan MS. Schizophrenia, "just the facts" 4. Clinical features and conceptualization. Schizophr Res. 2009;110(1-3):1-23.

8. Kitamura T, OkazakiY, Fujinawa A, Takayanagi I, Kasahara Y. Dimensions of schizophrenic positive symptoms: an exploratory factor analysis investigation. Eur Arch Psychiatry Clin Neurosci. 1998;248(3):130-135.
9. Foussias G, Remington G. Negative symptoms in schizophrenia: avolition and Occam's razor. Schizophr Bull. 2010;36(2): 359-369.

10. Lindenmayer JP, Brown E, Baker RW, et al. An excitement subscale of the Positive and Negative Syndrome Scale. Schizophr Res. 2004;68(2-3):331-337.

11. Saykin AJ, Gur RC, Gur RE, et al. Neuropsychological function in schizophrenia. Selective impairment in memory and learning. Arch Gen Psychiatry. 1991;48(7):618-624

12. Lieberman JA, Tollefson G, Tohen M, et al. Comparative efficacy and safety of atypical and conventional antip- sychotic drugs in first-episode psychosis: a randomized, double-blind trial of olanzapine versus haloperidol. Am J Psychiatry. 2003;160(8): 1396-1404.

13. McCreadie RG, Srinivasan TN, Padmavati R, Thara R. Extrapyramidal symptoms in unmedicated schizophrenia. $J$ Psychiatr Res. 2005;39(3):261-266.

14. Marder SR, Glynn SM, Wirshing WC, et al. Maintenance treatment of schizophrenia with risperidone or haloperidol: 2-year outcomes. Am J Psychiatry. 2003;160(8):1405-1412.

15. Leucht S, Corves C, Arbter D, Engel RR, Li C, Davis JM. Secondgeneration versus first-generation antipsychotic drugs for schizophrenia: a meta-analysis. Lancet. 2009;373(9657):31-41.

16. Leucht S, Komossa K, Rummel-Kluge C, et al. A meta-analysis of head-to-head comparisons of second-generation antipsychotics in the treatment of schizophrenia. Am J Psychiatry. 2009;166(2):152-163.

17. de Oliveira IR, Juruena MF. Treatment of psychosis: 30 years of progress. J Clin Pharm Ther. 2006;31(6):523-534.

18. Herz MI, Marder SR. Schizophrenia: Comprehensive Treatment and Management. Philadelphia: Lippincott Williams and Wilkins; 2002.

19. Stahl SM. Stahl's Essential Psychopharmacology: Neuroscientific Basis and Practical Applications. 3rd ed. New York: Cambridge University Press; 2008.

20. Roth BL, Sheffler DJ, Kroeze WK. Magic shotguns versus magic bullets: selectively non-selective drugs for mood disorders and schizophrenia. Nat Rev Drug Discov. 2004;3(4):353-359.

21. de Oliveira IR, Elkis H, Gattaz WF, et al. Aripiprazole for patients with schizophrenia and schizoaffective disorder: an open-label, randomized, study versus haloperidol. CNS Spectr. 2009;14(2):93-102.

22. Mailman RB, Murthy V. Third generation antipsychotic drugs: partial agonism or receptor functional selectivity? Curr Pharm Des. 2010;16(5):488-501.

23. Kerwin RW, Osborne S. Antipsychotic drugs. Medicine. 2000;28: $23-25$.

24. Lieberman JA, Stroup TS, McEvoy JP, et al. Effectiveness of antipsychotic drugs in patients with chronic schizophrenia. $N$ Engl $J$ Med. 2005;353(12):1209-1223

25. Miyamoto S, Duncan GE, Marx CE, Lieberman JA. Treatments for schizophrenia: a critical review of pharmacology and mechanisms of action of antipsychotic drugs. Mol Psychiatry. 2005;10(1): 79-104.

26. Ayuso-Gutiérrez JL, del Río Vega JM. Factors influencing relapse in the long-term course of schizophrenia. Schizophr Res. 1997;28(2-3): 199-206.

27. Perkins DO. Predictors of noncompliance in patients with schizophrenia. J Clin Psychiatry. 2002;63(12):1121-1128.

28. Thieda P, Beard S, Richter A, Kane J. An economic review of compliance with medication therapy in the treatment of schizophrenia. Psychiatr Serv. 2003;54(4):508-516.

29. Liu-Seifert H, Adams DH, Kinon BJ. Discontinuation of treatment of schizophrenic patients is driven by poor symptom response: a pooled post-hoc analysis of four atypical antipsychotic drugs. BMC Med. 2005;3:21.

30. Harvey PD, Rabinowitz J, Eerdekens M, Davidson M. Treatment of cognitive impairment in early psychosis: a comparison of risperidone and haloperidol in a large long-term trial. Am J Psychiatry. 2005;162(10):1888-1895. 
31. Rabinowitz J, Harvey PD, Eerdekens M, Davidson M. Premorbid functioning and treatment response in recent-onset schizophrenia. $\mathrm{Br}$ J Psychiatry. 2006;189:31-35.

32. Meltzer HY, Rabinowitz J, Lee MA, et al. Age at onset and gender of schizophrenic patients in relation to neuroleptic resistance. Am J Psychiatry. 1997;154(4):475-482.

33. Uçok A, Polat A, Genç A, Cakir S, Turan N. Duration of untreated psychosis may predict acute treatment response in first-episode schizophrenia. J Psychiatr Res. 2004;38(2):163-168.

34. Perkins DO, Gu H, Boteva K, Lieberman JA. Relationship between duration of untreated psychosis and outcome in first-episode schizophrenia: a critical review and meta-analysis. Am J Psychiatry. 2005;162(10):1785-1804.

35. Aleman A, Kahn RS, Selten JP. Sex differences in the risk of schizophrenia: evidence from meta-analysis. Arch Gen Psychiatry. 2003;60(6):565-571.

36. Correll CU, Malhotra AK, Kaushik S, McMeniman M, Kane JM. Early prediction of antipsychotic response in schizophrenia. Am J Psychiatry. 2003;160(11):2063-2065.

37. Leucht S, Busch R, Kissling W, Kane JM. Early prediction of antipsychotic nonresponse among patients with schizophrenia. J Clin Psychiatry. 2007;68(3):352-360.

38. Kinon BJ, Chen L, Ascher-Svanum H, et al. Predicting response to atypical antipsychotics based on early response in the treatment of schizophrenia. Schizophr Res. 2008;102(1-3):230-240.

39. Naber D, Lambert M. The CATIE and CUtLASS studies in schizophrenia: results and implications for clinicians. CNS Drugs. 2009;23(8):649-659.

40. Jones PB, Barnes TR, Davies L, et al. Randomized controlled trial of the effect on Quality of Life of second- vs first-generation antipsychotic drugs in schizophrenia: Cost Utility of the Latest Antipsychotic Drugs in Schizophrenia Study (CUtLASS 1). Arch Gen Psychiatry. 2006;63(10):1079-1087.

41. Kemp AS, Schooler NR, Kalali AH, et al. What is causing the reduced drug-placebo difference in recent schizophrenia clinical trials and what can be done about it? Schizophr Bull. 2010;36(3):504-509.

42. Kinon BJ, Potts AJ, Watson SB. Placebo response in clinical trials with schizophrenia patients. Curr Opin Psychiatry. 2011;24(2):107-113.

43. Walsh BT, Seidman SN, Sysko R, Gould M. Placebo response in studies of major depression: variable, substantial, and growing. JAMA. 2002;287(14):1840-1847.

44. Thase ME. The small specific effects of antidepressants in clinical trials: what do they mean to psychiatrists? Curr Psychiatry Rep 2011;13(6):476-482.

45. McMahon RP, Kelly DL, Boggs DL, et al. Feasibility of reducing the duration of placebo-controlled trials in schizophrenia research. Schizophr Bull. 2008;34(2):292-301.

46. Kemmler G, Hummer M, Widschwendter C, Fleischhacker WW. Dropout rates in placebo-controlled and active-control clinical trials of antipsychotic drugs: a meta-analysis. Arch Gen Psychiatry. 2005; 62(12):1305-1312.

47. Leber $P$. The use of placebo control groups in the assessment of psychiatric drugs: an historical context. Biol Psychiatry. 2000;47(8):699-706.

48. Aras G. Superiority, noninferiority, equivalence, and bioequivalencerevisited. Drug Inf J. 2001;35:1157-1164.

49. Streiner DL. Alternatives to placebo-controlled trials. Can J Neurol Sci. 2007;34 Suppl 1:S37-S41.

50. Oliveira IR, Nunes PM, Coutinho DM, Sena EP. Review of the efficacy of placebo in comparative clinical trials between typical and atypical antipsychotics. Rev Bras Psiquiatr. 2009;31(1):52-56.

51. Overall JE, Gorham DR. The brief psychiatric rating scale. Psychol Rep. 1962;10:10(3):799-812.

52. Kay SR, Fiszbein A, Opler LA. The positive and negative syndrome scale (PANSS) for schizophrenia. Schizophr Bull. 1987;13(2):261-276.

53. Correll CU, Kishimoto T, Nielsen J, Kane JM. Quantifying clinical relevance in the treatment of schizophrenia. Clin Ther. 2011;33(12): B16-B39.
54. Leucht S, Kane JM, Kissling W, Hamann J, Etschel E, Engel R. Clinical implications of Brief Psychiatric Rating Scale scores. Br J Psychiatry. 2005;187:366-371.

55. Leucht S, Kane JM, Kissling W, Hamann J, Etschel E, Engel RR. What does the PANSS mean? Schizophr Res. 2005;79(2-3):231-238.

56. Leucht S, Kane JM, Etschel E, Kissling W, Hamann J, Engel RR. Linking the PANSS, BPRS, and CGI: clinical implications. Neuropsychopharmacology. 2006;31(10):2318-2325.

57. Leucht S, Kane JM. Measurement-based psychiatry: definitions of response, remission, stability, and relapse in schizophrenia. J Clin Psychiatry. 2006;67(11):1813-1814.

58. Levine SZ, Rabinowitz J, Engel R, Etschel E, Leucht S. Extrapolation between measures of symptom severity and change: an examination of the PANSS and CGI. Schizophr Res. 2008;98(1-3):318-322.

59. Guy W. Clinical global impressions. In: Guy W, editor. ECDEUAssessment Manual for Psychopharmacology. Rockville, MD: US Department of Health, Education, and Welfare, Public Health Service, Alcohol, Drug Abuse, and Mental Health Administration, National Institute of Mental Health, Psychopharmacology Research Branch, Division of Extramural Research Programs; 1976.

60. Andreasen NC, Carpenter WT Jr, Kane JM, Lasser RA, Marder SR, Weinberger DR. Remission in schizophrenia: proposed criteria and rationale for consensus. Am J Psychiatry. 2005;162(3):441-449.

61. Andreasen NC. The Scale for the Assessment of Positive Symptoms (SAPS). Iowa City, IA: The University of Iowa; 1984.

62. Andreasen NC. The Scale for the Assessment of Negative Symptoms (SANS): conceptual and theoretical foundations. Br J Psychiatry Suppl. 1989;7:49-58.

63. Dellva MA, Tran P, Tollefson GD, Wentley AL, Beasley CM Jr. Standard olanzapine versus placebo and ineffective-dose olanzapine in the maintenance treatment of schizophrenia. Psychiatr Serv. 1997;48(12):1571-1577.

64. Tran PV, Dellva MA, Tollefson GD, Wentley AL, Beasley CM Jr. Oral olanzapine versus oral haloperidol in the maintenance treatment of schizophrenia and related psychoses. Br J Psychiatry. 1998;172:499-505.

65. Csernansky JG, Mahmoud R, Brenner R; for Risperidone-USA-79 Study Group. A comparison of risperidone and haloperidol for the prevention of relapse in patients with schizophrenia. $N$ Engl J Med. 2002;346(1):16-22.

66. de Sena EP, Santos-Jesus R, Miranda-Scippa A, Quarantini Lde C, Oliveira IR. Relapse in patients with schizophrenia: a comparison between risperidone and haloperidol. Rev Bras Psiquiatr. $2003 ; 25(4): 220-223$.

67. Schooler N, Rabinowitz J, Davidson M, et al. Risperidone and haloperidol in first-episode psychosis: a long-term randomized trial. Am J Psychiatry. 2005;162(5):947-953.

68. Peuskens J, Trivedi J, Malyarov S, et al. Prevention of schizophrenia relapse with extended release quetiapine fumarate dosed once daily: a randomized, placebo-controlled trial in clinically stable patients. Psychiatry (Edgmont). 2007;4(11):34-50.

69. Kramer M, Simpson G, Maciulis V, et al. Paliperidone extended- release tablets for prevention of symptom recurrence in patients with schizophrenia: a randomized, double-blind, placebo-controlled study. J Clin Psychopharmacol. 2007;27(1):6-14.

70. Addington D, Addington J, Schissel B. A depression rating scale for schizophrenics. Schizophr Res. 1990;3(4):247-251.

71. Karow A, Naber D. Subjective well-being and quality of life under atypical antipsychotic treatment. Psychopharmacology (Berl). 2002;162(1):3-10.

72. de Haan L, Nimwegen L, Amelsvoort T, Dingemans P, Linszen D. Improvement of subjective well-being and enduring symptomatic remission, a 5-year follow-up of first episode schizophrenia. Pharmacopsychiatry. 2008;41(4):125-128.

73. Juruena MF, de Sena EP, de Oliveira IR. Safety and tolerability of antipsychotics: focus on amisulpride. Drug Healthc Patient Saf. 2010;2:205-211 
74. Janssen B, Gaebel W, Haerter M, Komaharadi F, Lindel B, Weinmann S. Evaluation of factors influencing medication compliance in inpatient treatment of psychotic disorders. Psychopharmacology (Berl). 2006;187(2):229-236.

75. Olfson M, Mechanic D, Hansell S, Boyer CA, Walkup J, Weiden PJ. Predicting medication noncompliance after hospital discharge among patients with schizophrenia. Psychiatr Serv. 2000;51(2):216-222.

76. Voruganti L, Cortese L, Owyeumi L, et al. Switching from conventional to novel antipsychotic drugs: results of a prospective naturalistic study. Schizophr Res. 2002;57(2-3):201-208.

77. Thomas P, Alptekin K, Gheorghe M, Mauri M, Olivares JM, Riedel M. Management of patients presenting with acute psychotic episodes of schizophrenia. CNS Drugs. 2009;23(3):93-212.

78. Pollice R, Tomassini A, Malavolta M, et al. Subjective and psychopathological response in patients under different antipsychotic treatments: are there differences in real clinical practice? J Biol Regul Homeost Agents. 2008;22(1):83-91.

79. Rocca P, Crivelli B, Marino F, Mongini T, Portaleone F, Bogetto F. Correlations of attitudes toward antipsychotic drugs with insight and objective psychopathology in schizophrenia. Compr Psychiatry. 2008;49(2):170-176.

80. Schennach-Wolff R, Jäger M, Seemüller F, et al. Attitude towards adherence in patients with schizophrenia at discharge. J Psychiatr Res. 2009;43(16):1294-1301.

81. Diaz E, Neuse E, Sullivan MC, Pearsall HR, Woods SW. Adherence to conventional and atypical antipsychotics after hospital discharge. J Clin Psychiatry. 2004;65(3):354-360.

82. Naber D, Moritz S, Lambert M, et al. Improvement of schizophrenic patients' subjective well-being under atypical antipsychotic drugs. Schizophr Res. 2001;50(1-2):79-88.

83. Narvaez JM, Twamley EW, McKibbin CL, Heaton RK, Patterson TL. Subjective and objective quality of life in schizophrenia. Schizophr Res. 2008;98(1-3):201-208.

84. Huppert JD, Weiss KA, Lim R, Pratt S, Smith TE. Quality of life in schizophrenia: contributions of anxiety and depression. Schizophr Res.2001;51(2-3):171-180.

85. Kim JH, Ann JH, Kim MJ. Relationship between improvements of subjective well-being and depressive symptoms during acute treatment of schizophrenia with atypical antipsychotics. J Clin Pharm Ther. 2011;36(2):172-178.

86. Hansson L. Determinants of quality of life in people with severe mental illness. Acta Psychiatr Scand Suppl. 2006;429:46-50.

87. Eack SM, Newhill CE. Psychiatric symptoms and quality of life in schizophrenia: a meta-analysis. Schizophr Bull. 2007;33(5):1225-1237.

88. Hogan TP, Awad AG, Eastwood R. A self-report scale predictive of drug compliance in schizophrenics: reliability and discriminative validity. Psychol Med. 1983;13(1):177-183.

89. Naber D. A self-rating to measure subjective effects of neuroleptic drugs, relationships to objective psychopathology, quality of life, compliance and other clinical variables. Int Clin Psychopharmacol. 1995;10 Suppl 3:133-138.

90. Ware JE Jr, Sherbourne CD. The MOS 36-item short-form health survey (SF-36). I. Conceptual framework and item selection. Med Care. 1992;30(6):473-483.

91. EuroQol Group. EuroQol - a new facility for the measurement of health-related quality of life. Health Policy. 1990;16(3):199-208.

92. Leon AC, Olfson M, Portera L, Farber L, Sheehan DV. Assessing psychiatric impairment in primary care with the Sheehan Disability Scale. Int J Psychiatry Med. 1997;27(2):93-105.

Drug, Healthcare and Patient Safety

\section{Publish your work in this journal}

Drug, Healthcare and Patient Safety is an international, peer-reviewed open-access journal exploring patient safety issues in the healthcare continuum from diagnostic and screening interventions through to treatment, drug therapy and surgery. The journal is characterized by the rapid reporting of reviews, original research, clinical, epidemiological and
93. Nuechterlein KH, Green MF, Kern RS, et al. The MATRICS Consensus Cognitive Battery, part 1: test selection, reliability, and validity. Am J Psychiatry. 2008;165(2):203-213.

94. Ventura J, Cienfuegos A, Boxer O, Bilder R. Clinical global impression of cognition in schizophrenia (CGI-CogS): reliability and validity of a co-primary measure of cognition. Schizophr Res. 2008;106(1):59-69.

95. Pietrzak RH, Olver J, Norman T, Piskulic D, Maruff P, Snyder PJ. A comparison of the CogState Schizophrenia Battery and the Measurement and Treatment Research to Improve Cognition in Schizophrenia (MATRICS) Battery in assessing cognitive impairment in chronic schizophrenia. J Clin Exp Neuropsychol. 2009;31(7):848-859.

96. Collie A, Darekar A, Weissgerber G, et al Cognitive testing in earlyphase clinical trials: development of a rapid computerized test battery and application in a simulated Phase I study. Contemp Clin Trials. 2007;28(4):391-400.

97. Keefe RS, Poe M, Walker TM, Kang JW, Harvey PD. The Schizophrenia Cognition Rating Scale: an interview-based assessment and its relationship to cognition, real-world functioning, and functional capacity. Am J Psychiatry. 2006;163(3):426-432.

98. Wilk CM, Gold JM, Bartko JJ, et al. Test-retest stability of the Repeatable Battery for the Assessment of Neuropsychological Status in schizophrenia. Am J Psychiatry. 2002;159(5):838-844.

99. Keefe RS, Goldberg TE, Harvey PD, Gold JM, Poe MP, Coughenour L. The Brief Assessment of Cognition in Schizophrenia: reliability, sensitivity, and comparison with a standard neurocognitive battery. Schizophr Res. 2004;68(2-3):283-297.

100. Hurford IM, Marder SR, Keefe RS, Reise SP, Bilder RM. A brief cognitive assessment tool for schizophrenia: construction of a tool for clinicians. Schizophr Bull. 2011;37(3):538-545.

101. Kraus MS, Keefe RS. Cognition as an outcome measure in schizophrenia. Br J Psychiatry Suppl. 2007;50:s46-s51.

102. Nielsen RE, Nielsen J. Antipsychotic drug treatment for patients with schizophrenia: theoretical background, clinical considerations and patient preferences. Clin Med Ther. 2009;1:1053-1068.

103. Nemeroff CB, Kinkead B, Goldstein J. Quetiapine: preclinical studies, pharmacokinetics, drug interactions, and dosing. J Clin Psychiatry. 2002;63 Suppl 13:5-11.

104. Juruena MF, de Sena EP, de Oliveira IR. Specific mechanism of action of amisulpride in the treatment of schizophrenia and correlation with clinical response and tolerability. J Receptor Ligand Channel Res. 2011;4:49-55.

105. Kapur S, Seeman P. Does fast dissociation from the dopamine d(2) receptor explain the action of atypical antipsychotics?: A new hypothesis. Am J Psychiatry. 2001;158(3):360-369.

106. Henderson DC, Miley K. Glucose intolerance and diabetes in patients with schizophrenia. In: Meyer JM, Nasrallah HA, editors. Medical Illness and Schizophrenia. 2nd ed. Washington, DC: American Psychiatric Publishing, Inc; 2009.

107. Rummel-Kluge C, Komossa K, Schwarz S, et al. Head-to-head comparisons of metabolic side effects of second generation antipsychotics in the treatment of schizophrenia: a systematic review and meta-analysis. Schizophr Res. 2010;123(2-3):225-233.

108. Correll CU, Frederickson AM, Kane JM, Manu P. Equally increased risk for metabolic syndrome in patients with bipolar disorder and schizophrenia treated with second-generation antipsychotics. Bipolar Disord. 2008;10(7):788-797.

\section{Dovepress}

post-marketing surveillance studies, risk management, health literacy and educational programs across all areas of healthcare delivery. The manuscript management system is completely online and includes a very quick and fair peer-review system. Visit http://www.dovepress.com/ testimonials.php to read real quotes from published authors. 